\title{
Relationship closeness, habit and perceived subjective norms as predictors of volunteer role identity in school-based mentoring programmes
}

\author{
Maura Pozzi, Daniela Marzana and Elena Marta
}

Psychology Department, Università Cattolica del Sacro Cuore, Milano, Italy and CERISVICO-Research Centre on Community Development and Organisational Quality of Life, Università Cattolica del Sacro Cuore, Brescia, Italy

\section{Maria Luisa Vecina}

Departamento de Psicología Social, del Trabajo y Diferencial, Universidad Complutense de Madrid, Madrid, Spain, and

\section{Giovanni Aresi}

\section{Psychology Department, Università Cattolica del Sacro Cuore, Milano, Italy and CERISVICO-Research Centre on Community Development and Organisational Quality of Life, Università Cattolica del Sacro Cuore, Brescia, Italy}

\begin{abstract}
Purpose - This study aimed to examine factors associated with volunteer role identity in mentors of schoolbased mentoring programmes.

Design/methodology/approach - Drawing on established theoretical models of volunteerism (the Role Identity Model), and research and theory on mentoring programmes, an integrated model of predictors of mentor volunteer role identity was tested. Seventy-one mentors ( 63 females, mean age 36 years) completed a survey with measures of habit, subjective norms, satisfaction with the mentor-mentee relationship, relationship closeness, social skills and mentor role identity. Path analysis was used for data analysis.

Findings - Fit indexes revealed an acceptable fit to the data. There were six significant paths. Habit and subjective norms were directly related to role identity. The association between mentor role identity and two further predictors, satisfaction with the mentor-mentee relationship and social skills was respectively fully and partially mediated by relationship closeness.

Practical implications - Findings can inform mentoring programmes in supporting mentors to develop a close relationship with their mentees and promote the development of a role identity as a volunteer among mentors. A stronger role identity is in turn expected to enhance mentor retention in the programme.

Originality/value - An important and novel finding of this study is that relationship closeness contributes to mentors developing a volunteer role identity. Also, for the first time, the importance for mentors of support from significant others in fostering sustained volunteer engagement has been examined.
\end{abstract}

Keywords School-based mentoring, Volunteers, Volunteer role identity, Relationship closeness, Children at risk, Italy

Paper type Research paper

(C) Maura Pozzi, Daniela Marzana, Elena Marta, Maria Luisa Vecina and Giovanni Aresi. Published by Emerald Publishing Limited. This article is published under the Creative Commons Attribution (CCBY 4.0) licence. Anyone may reproduce, distribute, translate and create derivative works of this article (for both commercial and non-commercial purposes), subject to full attribution to the original publication and authors. The full terms of this licence may be seen at http://creativecommons.org/licences/by/4.0/legalcode

The authors thank all mentors for sharing their experience.
Volunteer role identity in mentoring programmes

Received 6 May 2020 Revised 18 August 2020 2 October 2020 27 October 2020 Accepted 1 November 2020 


\section{IJMCE 10,1}

\section{Introduction}

Supportive, intergenerational relationships with non-parent adults have been recognised as key resources for the healthy development of children (Scales et al., 2006). However, because of changes occurring in families and societal norms, such relationships may be less readily available for children than in the past (Jekielek et al., 2002; Rhodes et al., 2005). Mentoring facilitates the establishment of a relationship between an older or more experienced nonparental individual and younger or less experienced mentee. The mentor provides guidance and support to the mentee over time (Kanchewa et al., 2017). From a positive youth development perspective, mentoring is a way to address the issue of the lack of supportive adults in the lives of many children (Lerner et al., 2014).

An increasing number of formal mentoring programmes across the world offer young people access to supportive non-parental adults (MENTOR, 2015). Programmes generally focus on children or adolescents at risk of poor academic, behavioural or health outcomes. Typically, mentors are trained volunteer adults who are matched with mentees by the programme through a variety of criteria (e.g. socio-demographic characteristics, geographical proximity, common interests). Mentors and mentees meet periodically at school or in other public places. The quality of the mentor-mentee relationship is considered a key active ingredient of mentoring programmes. (Rhodes, 2005; Rhodes and DuBois, 2008) theorised that the mentoring relationship contributes to children's socio-emotional, cognitive and identity development through role modelling and the provision of emotional support and positive feedback. Furthermore, a relationship with a mentor can serve as a corrective experience for children who may have unsatisfying relationships with other adults in their lives (Rhodes, 2005). Mentoring has been used in a variety of settings, including schools, as an effective intervention strategy leading to positive child outcomes across behavioural, social, emotional and academic domains (O'Rourke, 2016; Raposa et al., 2019).

Because the majority of mentors in today's formal youth mentoring programmes are volunteers, their retention is key to the functioning of interventions and the achievement of the intended outcomes for youth (Stukas et al., 2013). Supporting mentors to stay on the programme also translates into benefits for the programme because, for example, it reduces the burden on staff to recruit and train new mentors and reduces early match termination (MENTOR, 2015). Premature match termination has important implications because it is associated with unfavourable outcomes for youth. There is indeed evidence that a minimum of 24 weeks of match duration is required for the relationship to develop and determine any benefit (Grossman et al., 2012).

Volunteering can be defined as a form of organised prosocial behaviour planned and maintained over time that benefits strangers and develops within a structure. Mentoring programmes can be understood in light of theoretical frameworks of volunteerism (Finkelstein, 2010; Marta and Pozzi, 2007; Marta and Santinello, 2010; Omoto and Snyder, 1995; Penner, 2002). Because volunteer role identity is key to their commitment to and continuation of their work (Grube and Piliavin, 2000), this study attempted to integrate theoretical models developed in the general psychological literature on volunteerism to examine factors involved in the development of a volunteer role identity among mentors in school-based mentoring programmes.

\section{Volunteer role identity and mentor commitment}

Classical work in social psychology literature distinguished between three components of one's identity (Linville and Carlston, 1994; Stryker, 1986; Thoits and Virshup, 1997; Turner, 1978). Personal identity consists of self-definitions in terms of personal characteristics, social identity reflects the identification of the self with a social group or category and role identity is the definition of self as a person who performs a particular social role. The role identity 
model (Callero et al., 1987; Piliavin and Callero, 1991) was developed to conceptualise this latter component of one's identity. This theory states that individuals engage in voluntary actions because they have developed a strong volunteer or service identity. As volunteering becomes part of their identity (i.e. a role identity as a volunteer), it drives continued volunteer actions because the individual strives to behave in concert with the changed self-concept in a virtuous cycle. Prior research has consistently shown that the strength of one's role identity correlates with the voluntary donation of time, money and even blood (Grube and Piliavin, 2000; Lee et al., 1999; Piliavin and Siegl, 2007). Continued participation in a mentoring programme can facilitate a process of internalisation of the volunteer role, which is adopted as a component of the self, an identity or role identity (Piliavin and Callero, 1991). Such internalisation ultimately promotes volunteer engagement, identification with the programme and long-term commitment (Stukas et al., 2013).

\section{Factors contributing to volunteer role identity}

There are at least three key factors involved in the development of a volunteer identity. First, despite established theoretical frameworks of youth mentoring (Keller, 2005; Noufou, 2014; Rhodes et al., 2006; Taylor and Porcellini, 2013) considering influences of external social networks (e.g. mentees' family, programme staff and peers as part of the organisational culture) in supporting mentoring matches, little attention has been paid to the role of other social referents, including mentors' significant others (e.g. family members and close friends). The theory of planned behaviour (TPB; Ajzen, 1985, 2011) states that subjective norms (i.e. the perceived social approval of engaging or not engaging in a behaviour) are essential in the process of deciding to volunteer (Brayley et al.,2015). In the mentoring context, this means that when mentors feel the support of significant others, they are more likely to stay engaged in the programme and continue mentoring. This theory has received empirical support across many fields, and its value as a theory for explaining volunteering has been demonstrated in a variety of populations and settings, including young adults (Hyde and Knowles, 2013; Marta et al., 2014) and elderly people (Warburton and Terry, 2000; Warburton et al., 2001). The TPB has also been validated within the context of related helping behaviours such as charitable giving (Smith and McSweeney, 2007; van der Linden, 2011) and blood donation (Reid and Wood, 2008).

Second, the concept of habit can be used to explain repeated behaviours. Habits are generally understood as semi-automatic performances of well-learned behaviours (Charng et al., 1988; Wood and Rünger, 2016). The more an individual performs a behaviour, the more likely it is that the behaviour will become a habit. Thus, past repeated behaviours can be an indicator of habit. Mentoring is a form of repeated behaviour: mentors meet multiple times with their mentees over a relatively long period, and they can be part of a number of matches over time. Importantly, repeated behaviours (i.e. having been a mentor for some time) can contribute to the construction of a role identity as a volunteer mentor.

Third, Stryker (1980) highlighted the importance of social relationships in the definition of one's self and role identity. In mentoring programmes, the mentor-mentee relationship is a key factor, and youth development goals can be achieved only to the extent that the mentor and youth forge a strong connection characterised by mutual respect, trust and empathy (Rhodes, 2005). The quality of this relationship can contribute to mentors developing a selfconcept that includes being a mentor and, consequently, a role identity as a volunteer. Even though relationship quality is a multidimensional construct (McMorris et al., 2018), closeness is considered its organising construct throughout mentoring literature (Nakkula and Harris, 2013). It is a key indicator of relationship quality (DuBois and Neville, 1997; Herrera et al., 2007; Parra et al., 2002) and can affect the likelihood of achieving mentoring intended outcomes (Bayer et al., 2015). Importantly, mentor-mentee relationship closeness can contribute to volunteer role identity development. Relationship closeness can be, in turn, determined by mentors' social skills (i.e. the ability to provide verbal and non-verbal
Volunteer role identity in mentoring programmes 
IJMCE 10,1

\section{0}

responses that are adequate to the situation; Herrera and Karcher, 2013; Lorr et al., 1991; Parra et al., 2002) and satisfaction with the relationship (Herrera et al., 2007). More specifically, in the Omoto and Snyder (2002) model of volunteerism, the interpersonal relationships between volunteers and recipients of their services (i.e. mentors and mentees in the case of mentoring programmes) have been examined. Mentoring programmes are essentially relationshipbased interventions, and volunteers have high expectations for the quality of such relationships. Mentors enter the relationship with a strong desire to make a positive difference in the lives of young people, though they may be easily discouraged if they feel unable to develop strong ties with their mentees (Spencer, 2007). The degree of their satisfaction in regard to this relationship is key to maintaining the commitment to the relationship and the programme overall (Omoto et al., 1998).

In sum, there is evidence that mentoring relationship closeness serves as an important mechanism for change in mentee outcomes, though little is known in regard to relationship closeness outcomes for mentors and more specifically how it affects their mentor role identity.

\section{Aims and hypotheses}

This study aimed to examine factors associated with the volunteer role identity of mentors. The role identity model (Callero $\mathrm{et} \mathrm{al.,} \mathrm{1987;} \mathrm{Piliavin} \mathrm{and} \mathrm{Callero,} \mathrm{1991)} \mathrm{and} \mathrm{theories} \mathrm{describing}$ factors involved in repeated behaviours (i.e. TPB) provided the overall theoretical framework. Figure 1 depicts the overall conceptual model. We expected habit (Hp1) and subjective norms (Hp2) to be positively associated with developing a mentor role identity. In addition, by drawing on the literature on the importance of match quality in mentoring programmes, we expected the association between satisfaction with the mentor-mentee relationship (Hp3) and mentors' social skills (Hp4) with mentor role identity to be, respectively, fully and partially mediated by relationship closeness (Hp5). For sensitivity analysis purposes, an alternative model considering satisfaction with mentor-mentee relationship as the mediator between relationship closeness and mentor role identity was considered (alternative Hp5).

\section{Method}

\section{Data collection}

Researchers contacted organisations that were conducting school-based mentoring programmes in Italy. These were the Società Umanitaria (Programma Mentore), Telefono Azzurro (One-to-One Programme) and some Catholic parishes. (For an example of how these

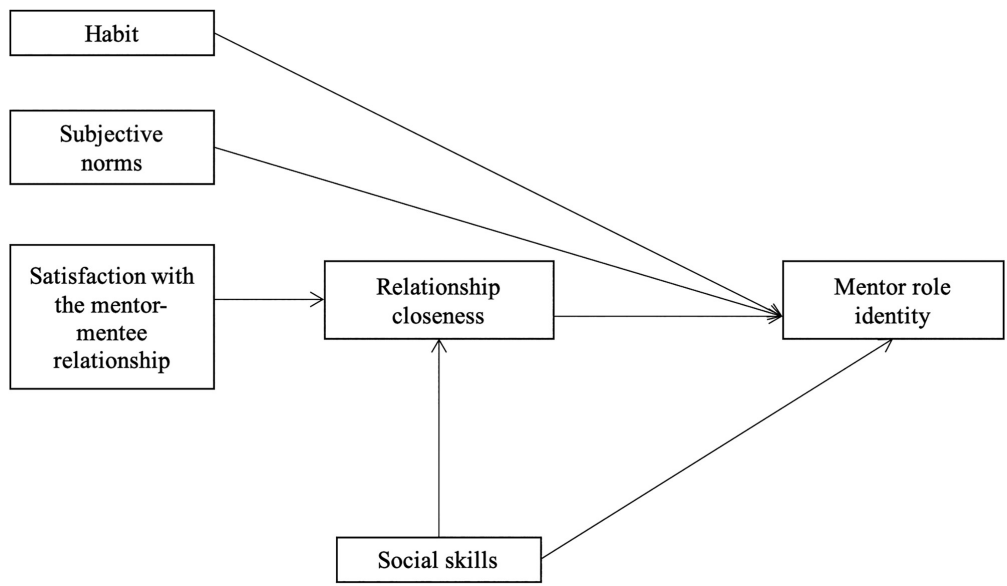

Figure 1.

Theoretical model of predictors of mentor role identity 
programmes work, see Aresi et al., 2020.) Programme managers were informed about the study and asked to disseminate a survey questionnaire to mentors within their organisation. The university ethical protocol was followed: This includes obtaining signed informed consent from participants (both programme managers and volunteers in this case), the right for participants to withdraw at any time and anonymisation of any data collected. All mentors were informed of the research aims and were asked to voluntarily participate in the study. Participants completed a paper-and-pencil self-report questionnaire. Participants were not compensated for taking part in the research.

\section{Measures}

Habit. Habit was defined as a "semi-automatic performance of a well-learned behaviour", and past repeated behaviours are an indicator of habit. Habit was measured by a single item: "How long have you been volunteering as a mentor?" Participants indicated how many years they had been mentoring.

Subjective norms. Two ad hoc items ("People I care about think it is correct to give time to help young people in need" and "People I care about think it's a good thing I'm volunteering") were used to measure subjective norms. Participants responded on a five-point Likert scale $(1=$ not at all; $5=$ very much).

Satisfaction with the mentor-mentee relationship. Satisfaction with the relationship was measured using an ad hoc item: "In general, I am very satisfied with the relationship with my mentee". Participants responded on a five-point Likert scale $(1=$ totally disagree; $5=$ totally agree).

Relationship closeness. Relationship closeness was measured using a 26 -item scale that included a modified version of the Relationships Closeness Inventory (RCI, 16 items; Berscheid et al., 1989) and Sternberg's (1997) Triangular Love Scale (TLS, 10 items). The development of the RCI was based upon the concept of interdependence as proposed by Kelley et al. (1983). The RCI includes three subscales (frequency, diversity and strength). In our study, the strength subscale was used to assess the degree of perceived influence each relationship partner had over the other. The intimacy subscale (10 items) of the TLS (Sternberg, 1997) was used. Participants responded using a five-point Likert scale ( 1 = strongly disagree; $5=$ strongly agree). Item examples are "My mentee influences the way I feel about myself" (RCI modified scale) and "I have a good relationship with my mentee" (Sternberg intimacy subscale).

Social skills. Social skills were measured using a three-item scale drawn from the social skills inventory (Riggio, 1986). These items measure social skills, such as social expressivity, social sensitivity and social control, within the verbal/social domain. Participants responded on a five-point Likert scale ( $1=$ totally disagree; $5=$ totally agree). A sample item is "I usually take the initiative to introduce myself to strangers".

Mentor role identity. Mentor role identity was measured using the eight-item Role Identity Scale (Callero et al., 1987). Participants responded on a five-point Likert scale $(1=$ strongly disagree; 5 = strongly agree). Items examples are "To be a mentor means more than to do mentoring service", "To mentor is an important part of my identity" and "I'm proud to belong to my mentor group".

\section{Data analysis}

Path analyses were used to investigate predictors of relationship affective quality and mentor role identity in accordance with the hypothesised theoretical model (see Figure 1). The software Amos 5 (Arbuckle, 2003) was used. Guidelines indicate the adequacy of a path analysis model, which is determined by a chi-square test $\left(\chi^{2}\right)$. This test evaluates how well the covariance matrix implied by the model fits the covariance matrix of the observed data.
Volunteer role identity in mentoring programmes 
IJMCE

10,1

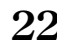

However, because the chi-square is heavily influenced by sample size (Bollen and Long, 1994), additional fit indices are generally used (Bentler, 1990; Jöreskog and Sörbom, 2004). The comparative fit index (CFI) has been proposed as the most appropriate fit index because it has a 0-1 range, has a small sampling variability and is not affected by sample size (Bentler, 1990; Garrett et al., 1994). In addition, the root means square error of approximation (RMSEA) was used to identify the acceptable error level. Indices lower than 0.080 are considered acceptable (Bollen, 1989). Its 90\% confidence interval index is also reported. The mediating effect of relationship closeness was tested using the accelerated-bias-corrected bootstrap estimation procedure, which yields the most accurate confidence intervals (CIs) for the indirect effects (MacKinnon et al., 2004). In the procedure, the given sample size was randomly resampled 10,000 times with replacement, and then 10,000 estimations of the indirect effect were calculated. When the $95 \%$ CI for an indirect effect did not include zero, the indirect effect was significant. An a priori power analysis was conducted to determine the minimum sample size. Results indicated that recruitment of 67 mentors was required to detect $>0.30$ significant associations among variables at $p<0.05$ with $80 \%$ power.

\section{Results \\ Participants}

A total of 112 mentors were contacted; 80 agreed to take part in the study. Nine participants with missing data were excluded, leading to a sample of 71 . The mean age was 36 years $(S D=16.41$; range $18-68)$, and 45 were female $(63 \%)$. A total of $42.2 \%$ of the participants had completed a master's degree, $42.3 \%$ high school degree, $14.1 \%$ had a lower degree and $1.4 \%$ had completed a $\mathrm{PhD}$ programme. The majority were single/not married $(62 \%)$. The remainder were married, divorced or widowed. A total of $22.5 \%$ had a full-time job, $25.4 \%$ were retired or unemployed, $25.4 \%$ were students and $15.5 \%$ both worked and studied at the same time. Seven percent were working part-time, and $4.2 \%$ were looking for a job. The majority $(68.1 \%)$ were involved in volunteerism from 1 to 5 hours per week, $31.9 \%$ from 6 to $15 \mathrm{~h}$ per week.

\section{Path analyses testing proposed model}

Descriptive statistics and correlations between variables are presented in Table 1 . With the only exception of the variable habit, the data showed a normal univariate distribution given that most skewness and kurtosis values fell within the range of -1.0 to +1.0 . The variable habit presented values of asymmetry and kurtosis above the threshold because of the presence of two outlier cases of mentors with $>20$ years of experience. Inspection of scatter plots demonstrated there was no major violation of the linearity of the relationship between the independent and dependent variables. Residuals were not correlated to any independent variable (all $p s>0.05$ ). Multicollinearity was not an issue because there was no absolute

Table 1.

Means, standard deviations and correlations between variables

\begin{tabular}{lccccccccc}
\hline & $M$ & SD & 1 & 2 & 3 & 4 & 5 & 6 \\
\hline 1. Habit & 5.13 & 4.46 & 1 & 0.135 & 0.124 & 0.052 & -0.027 & $0.309 * *$ \\
2. Subjective norms & 3.87 & 0.71 & - & 1 & 0.139 & $0.248^{*}$ & 0.201 & $0.350 * *$ \\
3. Satisfaction with the mentor-mentee & 3.83 & 0.94 & - & - & 1 & $0.341^{* *}$ & 0.147 & 0.052 \\
$\quad$ relationship & & & & & & & & & \\
4. Relationship closeness & 2.63 & 0.46 & - & - & - & 1 & $0.299 *$ & $0.397 * *$ \\
5. Social skills & 3.24 & 0.61 & - & - & - & - & 1 & $0.450^{* *}$ \\
6. Mentor role identity & 3.80 & 0.75 & - & - & - & - & - & 1 \\
Note(s): $* * p<0.01 ; * p<0.05$ & & & & & & & & \\
\hline
\end{tabular}


correlation coefficient of $>0.7$ among two or more predictors. This is confirmed by values of the variance inflation factor for each predictor being below 10, the highest being 1.2.

Figure 2 shows results of the model. The chi-squared test was not significant. This indicates that the empirical data did not differ from the theoretical model $\left(\chi^{2}(d f)=12.604(9)\right.$; $p=0.181)$. The $\chi^{2} / d f$ ratio was deemed acceptable $(<2)\left(\chi^{2} / d f=1.400\right)$. CFI of 0.924 was acceptable, as well as the RMSEA $(0.076$ [0.000 -0.165]. There were six significant paths. Mentor role identity had two direct predictors: volunteering habit $(\mathrm{Hp} 1)$ and subjective norms in regard to this behaviour (Hp2). The association between mentor role identity and two further predictors, satisfaction with the mentor-mentee relationship (Hp3) and social skills (Hp4) was respectively fully and partially mediated by relationship closeness (Hp5). The indirect effect of satisfaction with the relationship on role identity was significant (indirect effect $=0.087, p<0.01,95 \% \mathrm{CI}=[0.016,0.208]$ ), as well as that of social skills (indirect effect $=0.073, p<0.05,95 \% \mathrm{CI}=[0.002,0.164])$. The direct effects of satisfaction with the relationship and social skills were not significant $(\beta=-0.163, p>0.05)$, whereas the direct effect of social skills was significant $(\beta=0.367, p<0.001)$. All hypotheses were confirmed.

Test of the alternative model considering satisfaction with mentor-mentee relationship as the mediator between relationship closeness and mentor role identity (alternative Hp5) resulted in a poor fit $\left(\chi^{2}(d f)=15,673(8) ; p=0.047\right)$. The $\chi^{2} / d f$ ratio was deemed acceptable $(<2)\left(\chi^{2} / d f=1.959\right)$, though CFI (0.838) and RMSEA (0.117 [0.012 -0.203]) were below acceptable levels. The association between satisfaction with the relationship and mentor role identity was not significant. Therefore, no evidence of such mediation effect was found.

\section{Discussion}

The work of mentors is crucial to the achievement of mentoring programmes' intended outcomes. By drawing on established theoretical frameworks of volunteerism (Callero et al., 1987; Piliavin and Callero, 1991) and research and theory on mentoring interventions (Rhodes, 2005), this study examined factors associated with the development of a role identity as a volunteer by mentors in school-based mentoring programmes.

This is the first study that has attempted to empirically test a social identity model - the role identity model - in the mentoring context. Findings indicate that volunteer role identity is

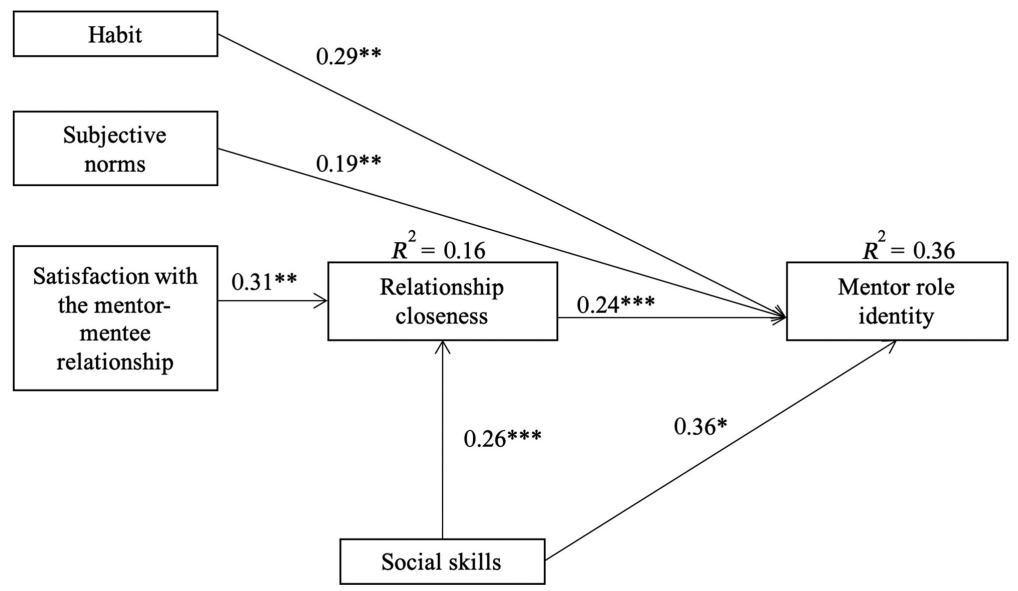

Note(s): Standardised coefficients are reported. All paths are significant.

$* p<0.05, * * p<0.01, * * * p<0.001$
Volunteer role identity in mentoring programmes

23
Figure 2. Path analysis model 
IJMCE 10,1

related to the extent mentors have developed the habit of being engaged in volunteering and their perception that important people around them support and approve their commitment. Continued participation in a mentoring programme can be understood as a habit developed over time, and results of this study suggest that having been a mentor for some time may facilitate a process of internalisation of the volunteer role and therefore be related to greater commitment to the programme in the long run (Piliavin and Callero, 1991; Piliavin et al., 2002). Previous research has demonstrated that opportunities for involvement in prosocial activities, such as mentoring, play an important role in the development of role identity as a volunteer (Flanagan, 2004; Piliavin et al., 2002). These activities offer individuals opportunities to connect and collaborate with others and promote solidarity (Flanagan, 2004), thus further establishing a role identity as a volunteer (Flanagan et al., 2005).

In accordance with applications of TPB to voluntary action (Brayley et al., 2015), results of this study underscore the importance of mentors feeling supported by others. Modelling and encouragement are important factors in the development of social and role identities (Dovidio et al., 2006). Modelling refers to the idea that people observe relevant others (Nesbit, 2012; Perks and Konecny, 2015; Quaranta and Dotti Sani, 2016). Engagement in prosocial behaviour and approval and encouragement by significant others to perform such behaviour are believed to induce prosocial behaviour in the observant. Results of this study indicate mentors' social identity as a volunteer is related to feeling of support from significant others. These results offer a new perspective to understand mentors' commitment to the programme because it complements research revealing the relevance of the quality of the programme and the support offered to mentors (Herrera and Karcher, 2013; MENTOR, 2015). Higher levels of staff monitoring and support have been found to be associated with greater relationship quality because mentors who are struggling in their relationship may receive guidance and support (Herrera et al., 2013). Social approval sought from important people in mentors' lives is less instrumental and more emotional but can still be important to sustain their engagement and commitment to the programme.

In this study, the connections between volunteer role identity and two further predictors, satisfaction with the mentor-mentee relationship and social skills were mediated by mentoring relationship closeness. The mentoring literature (Bayer et al., 2015; DuBois and Neville, 1997; Grossman and Rhodes, 2002; Langhout et al., 2004, 2014; Rhodes et al., 2005; Spencer, 2006) highlights the importance of the mentor-mentee relationship in achieving positive outcomes for youth. An important and novel finding of this study is that relationship closeness also contributes to mentors developing a role identity as a volunteer. Importantly, mentors use social skills acquired in their contexts of growth and training to benefit the mentoring relationship (Felice and Tagliavini, 2004; Herrera et al., 2007; Parra et al., 2002). In accordance with previous studies in this field (McMorris et al., 2018), this highlights the importance for programmes of developing mentor social skills and continuously sustaining them, because the expressivity, sensitivity and sense control in the relation with a fragile child enhance the sense of closeness in the mentor-mentee bond.

In addition, results of this study are consistent with those of the general volunteerism literature showing that mentors gain personal satisfaction from having voluntarily dedicated themselves to people in need of support (Marzana et al., 2010). Our results expand upon such literature by demonstrating that this in turn can foster mentor-mentee relationship closeness. Rhodes (2005) concluded that positive mentoring relationships are characterised by the lack of disappointment and the presence of satisfaction for the relationship with the mentee.

\section{Implications for research and mentoring practice}

Findings of this study have several implications for future research and practice. First, mentor role identity can play an important role in volunteers' commitment to and retention in 
mentoring programmes, and therefore in the achievement of greater match length. This is important because avoiding early termination is crucial to achieve mentoring programmes intended outcomes for youth (DeWit et al., 2016; Grossman et al., 2012) and reducing volunteer turnover, which in turn diminishes the burden on staff to recruit and train new mentors (MENTOR, 2015). Strategies that foster mentors' role identity as volunteers could be incorporated into standard practice for orienting and training new mentors and for providing ongoing support and supervision. After orientation and initial training, support offered to mentors often declines (Stukas et al., 2013); instead, it is important to focus on the experience of mentoring and encourage mentors to enhance their skills to successfully develop effective mentoring relationships and feel satisfied. For example, it might be useful to offer mentors participation in support groups that contribute to reinforce their role identity as mentors through the creation of a social network with shared experiences and expectations of mentoring. Future research could further examine how role identity is developed over time and empirically test whether an enhanced identity as a volunteer predicts longer match duration and long-term commitment to the programme.

Second, the role of the social environment in fostering sustained volunteer engagement has been well examined (Rossi et al., 2016), though it has received little attention in the mentoring literature. This study examined the effect of the approval from family and close friends in the development of a volunteer role identity. Future research could investigate the effect of approval from other social referents, including fellow mentors or other people (e.g. colleagues). In accordance, mentoring programmes may develop strategies to help mentors feel supported by important people in their lives, for example, by organising activities and social events with them.

Third, the subjective benefits mentors get from their voluntary work can foster their engagement in the programme. For example, they can derive pleasure and satisfaction by expressing their prosocial values, learning new social skills, receiving the gratitude of their mentees, being productive and creative and enriching their personal identity and their social network (Livi et al., 2019). Giving (i.e. volunteering) is indeed a way of getting (Piliavin and Siegl, 2007, 2015). Mentoring programmes should therefore facilitate the matching between mentors' personal motivations and tasks that result in satisfaction and positive volunteer outcomes (Clary et al., 1998; Finkelstein, 2008; Hustinx, 2010; Tschirhart et al., 2001). In addition, as with other types of relational volunteering (Pozzi et al., 2017), it is necessary to consider the quality of the mentor-mentee relationship and the particular experience of mentors (Bayer et al., 2015; Rhodes, 2005; Rhodes and DuBois, 2008). It is of fundamental importance to supervise the progress of these relationships and the capacity of mentors to deal with any difficulties

\section{Limitations}

The present study has several limitations that are noteworthy. First, the cross-sectional design of the study constrains the interpretation of causal effects. Further research with longitudinal designs using larger samples is needed to better examine the causal relationships and mediation effects. Second, the relatively small sample size and relatively high proportion of single respondents and respondents with certain religious affiliations, restrict representativeness and have implications for the potential transferability of the findings. A third limitation is that this study employed only self-report measures, which might be susceptible to response bias (e.g. social desirability). Moreover, the measures for habit, subjective norms and satisfaction were developed ad hoc and future research would benefit from the use of validated measures. Multiple methods for evaluation would be beneficial in future research, including data on to what extent intentions to stay on the programme reflect actual behaviour afterward. Fourth, satisfaction with the relationship was measured using a single item which may not have captured the full breadth of the construct and limited the possibility of addressing reliability issues.

\section{Volunteer role identity in mentoring programmes}


IJMCE

10,1

\section{Conclusions}

This study empirically investigated the applicability of theoretical models of voluntary action to mentoring programmes. Findings demonstrate the importance of match quality and closeness as a key component of mentors' engagement and their role identity as volunteers. This underscores the importance of considering mentors primarily as volunteers whose motivation and engagement need to be nurtured over time. Mentoring programmes can develop guidelines and practical strategies drawn from the literature on volunteerism to promote the development of role identity amongst their volunteer mentors.

\section{References}

Ajzen, I. (1985), "From intentions to actions: a theory of planned behavior", in Kuhl, J. and Beckmann, J. (Eds), Action Control: From Cognition to Behavior, Springer-Verlag, New York.

Ajzen, I. (2011), "The theory of planned behaviour: reactions and reflections", Psychology and Health, Vol. 26, pp. 1113-1127.

Arbuckle, J.L. (2003), Amos 18 User's Guide, Lawrence Erlbaum Associates, New Jersey.

Aresi, G., De Luca, M. and Marta, E. (2020), "Valutazione di processo di un programma di mentoring scolastico: una rilettura in ottica di Psicologia di Comunità [Process evaluation of a schoolbased mentoring programme: a Community Psychology perspective]", Psicologia di Comunità, Vol. 1, pp. 135-155.

Bayer, A., Grossman, J.B. and DuBois, D.L. (2015), "Using volunteer mentors to improve the academic outcomes of underserved students: the role of relationships", Journal of Community Psychology, Vol. 43, pp. 408-429.

Bentler, P.M. (1990), "Comparative fit indexes in structural models", Psychological Bulletin, Vol. 107, pp. 238-246.

Berscheid, E., Snyder, M. and Omoto, A.M. (1989), “The relationship closeness inventory: assessing the closeness of interpersonal relationships", Journal of Personality and Social Psychology, Vol. 57, pp. 792-807.

Bollen, K.A. (1989), Structural Equations with Latent Variables, John Wiley \& Sons, New York.

Bollen, K.A. and Long, J.S. (1994), Testing Structural Equation Models, Sage, Newbury Park, CA.

Brayley, N., Obst, P.L., White, K.M., Lewis, I.M., Warburton, J. and Spencer, N.M. (2015), "Examining the predictive value of combining the theory of planned behaviour and the volunteer functions inventory", Australian Journal of Psychology, Vol. 67, pp. 149-156.

Callero, P.L., Howard, J.A. and Piliavin, J.A. (1987), "Helping behavior as role behavior: disclosing social structure and history in the analysis of prosocial action", Social Psychology Quarterly, Vol. 50, pp. 247-256.

Charng, H.-W., Piliavin, J.A. and Callero, P.L. (1988), "Role identity and reasoned action in the prediction of repeated behavior", Social Psychology Quarterly, Vol. 51, pp. 303-317.

Clary, E.G., Snyder, M., Ridge, R.D., Copeland, J., Stukas, A.A., Haugen, J. and Miene, P. (1998), "Understanding and assessing the motivations of volunteers: a functional approach", Journal of Personality and Social Psychology, Vol. 74, pp. 1516-1530.

DeWit, D.J., DuBois, D., Erdem, G., Larose, S. and Lipman, E.L. (2016), “The role of program-supported mentoring relationships in promoting youth mental health, behavioral and developmental outcomes", Prevention Science, Vol. 17, pp. 646-657.

Dovidio, J.F., Piliavin, J.A., Schroeder, D.A. and Penner, L.A. (2006), The Social Psychology of Prosocial Behavior, Lawrence Erlbaum Associates Publishers, Mahwah.

DuBois, D.L. and Neville, H.A. (1997), "Youth mentoring: investigation of relationship characteristics and perceived benefits", Journal of Community Psychology, Vol. 25, pp. 227-234. 
Felice, A. and Tagliavini, A. (2004), CAMEO: Comparazione ed Analisi del Mentoring in Europa, Franco Angeli, Milano, Italy.

Finkelstein, M.A. (2008), "Volunteer satisfaction and volunteer action: a functional approach", Social Behavior and Personality: An International Journal, Vol. 36, pp. 9-18.

Finkelstein, M.A. (2010), "Individualism/collectivism: implications for the volunteer process", Social Behavior and Personality: An International Journal, Vol. 38, pp. 445-452.

Flanagan, C.A. (2004), "Volunteerism, leadership, political socialization, and civic engagement", in Lerner, R.M. and Steinberg, L.D. (Eds), Handbook of Adolescent Psychology.

Flanagan, C.A., Gill, S. and Gallay, L.S. (2005), "Social participation and social trust in adolescence: the importance of heterogeneous encounters", in Omoto, A.M. (Ed.), Processes of Community Change and Social Action, Lawrence Erlbaum Associates, Mahwah, New Jersey.

Garrett, P., Ferron, J., Ng'andu, N., Bryant, D. and Harbin, G. (1994), "A structural model for the developmental status of young children", Journal of Marriage and the Family, Vol. 56 No. 1, pp. 147-163, doi: 10.2307/352710.

Grossman, J.B. and Rhodes, J.E. (2002), "The test of time: predictors and effects of duration in youth mentoring relationships", American Journal of Community Psychology, Vol. 30, pp. 199-219.

Grossman, J.B., Chan, C.S., Schwartz, S.E.O. and Rhodes, J.E. (2012), "The test of time in school-based mentoring: the role of relationship duration and Re-matching on academic outcomes", American Journal of Community Psychology, Vol. 49, pp. 43-54.

Grube, J.A. and Piliavin, J.A. (2000), "Role identity, organizational experiences, and volunteer performance", Personality and Social Psychology Bulletin, Vol. 26, pp. 1108-1119.

Herrera, C. and Karcher, M.J. (2013), "School-based mentoring", in DuBois, D.L. and Karcher, M.J. (Eds), Handbook of Youth Mentoring, Sage Publications, Los Angeles.

Herrera, C., Grossman, J.B., Kauh, T.J., Feldman, A.F. and Mcmaken, J. (2007), Making a Difference in Schools: The Big Brothers Big Sisters School-Based Mentoring Impact Study, Public/Private Ventures, New York, NY.

Herrera, C., DuBois, D.L. and Grossman, J.B. (2013), The Role of Risk: Mentoring Experiences and Outcomes for Youth with Varying Risk Profiles, A Public/Private Ventures Project Distributed by MDRC, New York, NY.

Hustinx, L. (2010), "I quit, therefore I am?:Volunteer turnover and the politics of self-actualization", Nonprofit and Voluntary Sector Quarterly, Vol. 39, pp. 236-255.

Hyde, M.K. and Knowles, S.R. (2013), "What predicts Australian university students' intentions to volunteer their time for community service?”, Australian Journal of Psychology, Vol. 65, pp. 135-145.

Jekielek, S., Moore, K.A. and Hair, E.C. (2002), Mentoring Programs and Youth Development: A Synthesis, Child Trends, Washington, DC.

Jöreskog, K.G. and Sörbom, D. (2004), LISREL 8.7 for Windows, Scientific Software International, Lincolnwood, IL.

Kanchewa, S.S., Schwartz, S.E.O. and Rhodes, J.E. (2017), "Mentoring disadvantaged youth", in Clutterbuck, D.A., Kochan, F.K., Lunsford, L., Domínguez, N. and Haddock-Millar, J. (Eds), The Sage Handbook of Mentoring, Sage.

Keller, T.E. (2005), "The stages and development of mentoring relationships", in DuBois, D.L. and Karcher, M.J. (Eds), Handbook of Youth Mentoring, Sage, Thousand Oaks, CA.

Kelley, H.H., Berscheid, E., Christensen, A., Harvey, J.H., Huston, T.L., Levinger, G., Mcciintock, E., Peplau, L.A. and Peterson, D.R. (1983), Close Relationships, Freeman, New York.

Langhout, R.D., Rhodes, J.E. and Osborne, L.N. (2004), "An exploratory study of youth mentoring in an urban context: adolescents' perceptions of relationship styles", Journal of Youth and Adolescence, Vol. 33, pp. 293-306.

Volunteer role identity in mentoring programmes 
IJMCE 10,1

Langhout, R.D., Collins, C. and Ellison, E.R. (2014), "Examining relational empowerment for elementary school students in a yPAR program", American Journal of Community Psychology, Vol. 53, pp. 369-81.

Lee, L., Piliavin, J.A. and Call, V.R.A. (1999), "Giving time, money, and blood: similarities and differences”, Social Psychology Quarterly, Vol. 62, pp. 276-290.

Lerner, R.M., Napolitano, C.M., Boyd, M.J., Mueller, M.K. and Callina, K.S. (2014), "Handbook of youth mentoring", in DuBois, D.L. and Karcher, M.J. (Eds), Mentoring and Positive Youth Development, Sage, Thousand Oaks, CA.

Linville, P.W. and Carlston, D.E. (1994), "Social cognition and the self", in Devine, P.G., Hamilton, D.L. and Ostrom, T.M. (Eds), Social Cognition: Impact on Social Psychology, Academic Press, San Diego.

Livi, S., De Cristofaro, V., Theodorou, A., Rullo, M., Piccioli, V. and Pozzi, M. (2019), "When motivation is not enough: effects of prosociality and organizational socialization in volunteers' intention to continue volunteering", Journal of Community and Applied Social Psychology, Vol. 30 No. 3, pp. 249-261, doi: 10.1002/casp.2446.

Lorr, M., Youniss, R.P. and Stefic, E.C. (1991), “An inventory of social skills”, Journal of Personality Assessment, Vol. 57, pp. 506-520.

MacKinnon, D.P., Lockwood, C.M. and Williams, J. (2004), "Confidence limits for the indirect effect: distribution of the product and resampling methods", Multivariate Behavioral Research, Vol. 39, pp. 99-128.

Marta, E. and Pozzi, M. (2007), Psicologia del Volontariato, Carocci, Roma.

Marta, E. and Santinello, M. (2010), Il mentoring. Una lettura in ottica di psicologia di comunità, Unicopli, Milano.

Marta, E., Manzi, C., Pozzi, M. and Vignoles, V.L. (2014), "Identity and the theory of planned behavior: predicting maintenance of volunteering after three years", The Journal of Social Psychology, Vol. 154, pp. 198-207.

Marzana, D., Guiddi, P. and Marta, E. (2010), "Mentoring: gli interventi, i protagonisti, gli effetti”, in Marta, E. and Santinello, M. (Eds), Il Mentoring: Una rilettura in Ottica di Comunità, Unicopli, Milano, Italy.

McMorris, B.J., Doty, J.L., Weiler, L.M., Beckman, K.J. and Garcia-Huidobro, D. (2018), “A typology of school-based mentoring relationship quality: Implications for recruiting and retaining volunteer mentors", Children and Youth Services Review, Vol. 90, pp. 149-157.

MENTOR (2015), Elements of Effective Practice for Mentoring, 4th ed., Boston, MA.

Nakkula, M. J. and Harris, J.T. (2013), “Assessing mentoring relationships", in DuBois, D.L. and Karcher, M.J. (Eds), Handbook of Youth Mentoring, Sage, Thousand Oaks, CA.

Nesbit, R. (2012), "The influence of family and household members on individual volunteer choices", Nonprofit and Voluntary Sector Quarterly, Vol. 42, pp. 1134-1154.

Noufou, O. (2014), "Measuring and exploring factors affecting students' willingness to engage in peer mentoring", International Journal of Mentoring and Coaching in Education, Vol. 3, pp. 141-157.

O'Rourke, M. (2016), "The Life matters programme for developing life-skills in children: an evaluation”, International Journal of Mentoring and Coaching in Education, Vol. 5, pp. 144-157.

Omoto, A.M. and Snyder, M. (1995), "Sustained helping without obligation: motivation, longevity of service, and perceived attitude change among AIDS volunteers", Journal of Personality and Social Psychology, Vol. 68, pp. 671-686.

Omoto, A.M. and Snyder, M. (2002), "Considerations of community: the context and process of volunteerism”, American Behavioral Scientist, Vol. 45, pp. 846-867.

Omoto, A.M., Gunn, D.O. and Crain, A.L. (1998), "Helping in hard times: relationship closeness and the AIDS volunteer experience", in Derlega, V.J. and Barbee, A.P. (Eds), HIV \& Social Interaction, Sage, Thousand Oaks. 
Parra, G.R., DuBois, D.L., Neville, H.A., Pugh-Lilly, A.O. and Povinelli, N. (2002), "Mentoring relationships for youth: investigation of a process-oriented model", Journal of Community Psychology, Vol. 30, pp. 367-388.

Penner, L.A. (2002), "Dispositional and organizational influences on sustained volunteerism: an interactionist perspective", Journal of Social Issues, Vol. 58, pp. 447-467.

Perks, T.A. and Konecny, D. (2015), "The enduring influence of parent's voluntary involvement on their children's volunteering in later life", Canadian Review of Sociology/Revue Canadienne de Sociologie, Vol. 52, pp. 89-101.

Piliavin, J.A. and Callero, P. (1991), Giving Blood: The Development of an Altruistic Identity, John Hopkins University Press, Baltimore.

Piliavin, J.A. and Siegl, E. (2007), "Health benefits of volunteering in the Wisconsin longitudinal study", Journal of Health and Social Behavior, Vol. 48, pp. 450-464.

Piliavin, J.A. and Siegl, E. (2015), "Health and well-being consequences of formal volunteering", in Schroeder, D.A. and Graziano, W.G. (Eds), The Oxford Handbook of Prosocial Behavior, Oxford University Press, New York, NY.

Piliavin, J.A., Grube, J.A. and Callero, P.L. (2002), "Role as resource for action in public service", Journal of Social Issues, Vol. 58, pp. 469-485.

Pozzi, M., Pistoni, C. and Alfieri, S. (2017), "Verso una psicologia della partecipazione: una sistematizzazione teorica dei rapporti tra le azioni nel sociale [Toward a Psychology of Participation: a theoretical analysis of the relationship between actions in the social context]", Psicologia Sociale, Vol. 3, pp. 253-276.

Quaranta, M. and Dotti Sani, G.M. (2016), "The relationship between the civic engagement of parents and children: a cross-national analysis of 18 European countries", Nonprofit and Voluntary Sector Quarterly, Vol. 45, pp. 1091-1112.

Raposa, E.B., Rhodes, J., Stams, G.J.J.M., Card, N., Burton, S., Schwartz, S., Sykes, L.A.Y., Kanchewa, S., Kupersmidt, J. and Hussain, S. (2019), "The effects of youth mentoring programs: a meta-analysis of outcome studies", Journal of Youth and Adolescence, Vol. 48, pp. $423-443$.

Reid, M. and Wood, A. (2008), "An investigation into blood donation intentions among nondonors", International Journal of Nonprofit and Voluntary Sector Marketing, Vol. 13, pp. 31-43.

Rhodes, J.E. (2005), “A theoretical model of youth mentoring”, in DuBois, D.L. and Karcher, M.J. (Eds), Handbook of Youth Mentoring, Sage, Thousand Oaks, CA.

Rhodes, J.E. and DuBois, D.L. (2008), "Mentoring relationships and programs for youth", Current Directions in Psychological Science, Vol. 17, pp. 254-258.

Rhodes, J.E., Reddy, R., Roffman, J. and Grossman, J.B. (2005), "Promoting successful youth mentoring relationships: a preliminary screening questionnaire", Journal of Primary Prevention, Vol. 26, pp. 147-167.

Rhodes, J.E., Spencer, R., Keller, T.E., Liang, B. and Noam, G. (2006), “A model for the influence of mentoring relationships on youth development", Journal of Community Psychology, Vol. 34, pp. 691-707.

Riggio, R.E. (1986), “Assessment of basic social skills”, Journal of Personality and Social Psychology, Vol. 51, pp. 649-660.

Rossi, G., Lenzi, M., Sharkey, J.D., Vieno, A. and Santinello, M. (2016), "Factors associated with civic engagement in adolescence: the effects of neighborhood, school, family, and peer contexts", Journal of Community Psychology, Vol. 44, pp. 1040-1058.

Scales, P.C., Benson, P.L. and Mannes, M. (2006), "The contribution to adolescent well-being made by nonfamily adults: an examination of developmental assets as contexts and processes", Journal of Community Psychology, Vol. 34, pp. 401-413.
Volunteer role identity in mentoring programmes 
IJMCE 10,1

Smith, J.R. and McSweeney, A. (2007), "Charitable giving: the effectiveness of a revised theory of planned behaviour model in predicting donating intentions and behaviour", Journal of Community and Applied Social Psychology, Vol. 17, pp. 363-386.

Spencer, R. (2006), "Understanding the mentoring process between adolescents and adults", Youth and Society, Vol. 37, pp. 287-315.

Spencer, R. (2007), "I just feel safe with him': emotional closeness in male youth mentoring relationships", Psychology of Men and Masculinity, Vol. 8, pp. 185-198.

Sternberg, R.J. (1997), "Construct validation of a triangular love scale", European Journal of Social Psychology, Vol. 27, pp. 313-335.

Stryker, S. (1980), Symbolic Interactionism: A Social Structural Version, Benjamin/Cummings, Menlo Park, CA.

Stryker, S. (1986), "Identity theory: developments and extensions", in Yardley, K. and Honess, T. (Eds), Self and Identity: Psycho Social Perspectives, Wiley, Chichester.

Stukas, A.A., Clary, E.G. and Snyder, M. (2013), "Mentor recruitment and retention", in DuBois, D.L. and Karcher, M.J. (Eds), Handbook of Youth Mentoring, Sage Publications, Los Angeles.

Taylor, A. and Porcellini, L. (2013), "Family involvement", in DuBois, D.L. and Karcher, M.J. (Eds), Handbook of Youth Mentoring, Sage Publications.

Thoits, P.A. and Virshup, L.K. (1997), "Me's and we's: forms and functions of social identities", in Ashmore, R.D. and Jussim, L. (Eds), Self and Identity: Fundamental Issues, Oxford University Press, Oxford.

Tschirhart, M., Mesch, D.J., Perry, J.L., Miller, T.K. and Lee, G. (2001), "Stipended volunteers: their goals, experiences, satisfaction, and likelihood of future service", Nonprofit and Voluntary Sector Quarterly, Vol. 30, pp. 422-443.

Turner, R.H. (1978), "The role and the person”, American Journal of Sociology, Vol. 84, pp. 1-23.

van der Linden, S. (2011), "Charitable intent: a moral or social construct? A revised theory of planned behavior model”, Current Psychology, Vol. 30, pp. 355-374.

Warburton, J. and Terry, D.J. (2000), "Volunteer decision making by older people: a test of a revised theory of planned behavior", Basic and Applied Social Psychology, Vol. 22, pp. 245-257.

Warburton, J., Terry, D.J., Rosenman, L.S. and Shapiro, M. (2001), "Differences between older volunteers and nonvolunteers: attitudinal, normative, and control beliefs", Research on Aging, Vol. 23, pp. 586-605.

Wood, W. and Rünger, D. (2016), "Psychology of habit", Annual Review of Psychology, Vol. 67, pp. 289-314.

\section{Corresponding author}

Maura Pozzi be contacted at: maura.pozzi@unicatt.it

For instructions on how to order reprints of this article, please visit our website:

www.emeraldgrouppublishing.com/licensing/reprints.htm

Or contact us for further details: permissions@emeraldinsight.com 